\title{
Assessment of Efficacy of 2D Echo and Contrast Echo in Detection of Thrombus.
}

\author{
Monica Razdan', Bhupendra Chouhan ${ }^{2}$ \\ ${ }^{1}$ Senior Resident, ${ }^{2}$ Assistant Professor, Department of General Medicine, SAMC \& PGI Indore.
}

\section{Abstract}

Background: As echo is widely used to screen patients with coronary disease or heart failure at risk for LV thrombus, optimization of diagnostic strategies for thrombus detection is of substantial importance. Hence; we planned the present study to assess and compare the efficacy of 2D echo and contrast echo in detection of thrombus. Subjects and Methods: The present study included assessment and comparison of 2D echo and contrast echo in detection of thrombus. A total of 25 patients were included in the present study. Detailed demographic data and biochemical profile of all the patients was obtained. All the patients underwent both 2D echo and contrast echo. All the results were compiled in Microsoft excel sheet and were analysed by SPSS software. Results: 2D echo detected thrombus in 3 percent of the cases while the contrast echo detected thrombus in 12 percent of the cases. Significant results were obtained while comparing the prevalence of thrombus as detected by 2D echo and contrast echo. Conclusion: Efficacy of contrast echo s significantly higher than that of 2D echo in detecting LV thrombus.

Keywords: Contrast Echo, Thrombus.

Corresponding Author: Dr. Bhupendra Chouhan, Assistant Professor, Department of General Medicine, SAMC \& PGI Indore.

Received: February 2019

Accepted: March 2019

\section{Introduction}

Use of UCAs in echocardiography is not new. The utility of a strategy of echo contrast administration based on a-priori clinical risk for thrombus rather than non-contrast echo image quality is unknown. As echo is widely used to screen patients with coronary disease or heart failure at risk for $\mathrm{LV}$ thrombus, optimization of diagnostic strategies for thrombus detection is of substantial importance. ${ }^{[1-3]}$ Since the ultrasound characteristics of micro-bubbles are distinctly different from those of the surrounding blood cells and cardiac tissue, the backscatter that they produce result in intense echocardiographic signals, which are proportional to the blood volume. Thus, the LV cavity is enhanced compared with the surrounding heart muscle (which has relatively lower myocardial blood volume). ${ }^{[4-6]}$ Hence; we planned the present study to assess and compare the efficacy of 2D echo and contrast echo in detection of thrombus.

\section{Subjects and Methods}

The present study was conducted in the department of cardiology and it included assessment and comparison of $2 \mathrm{D}$ echo and contrast echo in detection of thrombus. A total of 25 patients were included in the present study. Detailed demographic data and biochemical profile of all the patients was obtained.

\section{$\underline{\text { Inclusion Criteria }}$}

- Age above 18 years.

- Patients presenting with clinical history and examination findings suggestive of Acute Myocardial Infarction.

All the patients underwent both 2D echo and contrast echo. All the results were compiled in Microsoft excel sheet and were analysed by SPSS software. Chi- square test and Mann Whitney $U$ test were used for assessment of level of significance. P- value of less than 0.05 was taken as significant.

\section{Results}

Table 1: Demographic data.

\begin{tabular}{|l|l|}
\hline Parameter & Value \\
\hline Mean age (years) & 52.5 \\
\hline Males & 15 \\
\hline Females & 10 \\
\hline Mean BMI (Kg/m2) & 27.6 \\
\hline
\end{tabular}

Table 2: Distribution of subjects according to presence of hypertension, diabetes and dyslipidemia.

\begin{tabular}{|l|l|l|}
\hline Parameter & Present & Value \\
\cline { 2 - 3 } & Absent & 10 \\
\hline \multirow{2}{*}{ Hiabetes mellitus } & Present & 15 \\
\cline { 2 - 3 } & Absent & 12 \\
\hline \multirow{2}{*}{ Dyslipidemia } & Present & 13 \\
\cline { 2 - 3 } & Absent & 11 \\
\hline
\end{tabular}


In the present study, a total of 25 patients were analyzed. Mean age of the patients of the present study was 52.5 years. Among these 25 patients, 15 were males while the remaining 10 were females. Mean BMI of the patients of the present study was $27.6 \mathrm{Kg} / \mathrm{m} 2$. 2D echo detected thrombus in 3 percent of the cases while the contrast echo detected thrombus in 12 percent of the cases. Significant results were obtained while comparing the prevalence of thrombus as detected by 2D echo and contrast echo.

Table 3: Prevalence of LV thrombus by 2D Echo and contrast Echo.

\begin{tabular}{|l|l|l|l|}
\hline LV thrombus & 2 D Echo & $\begin{array}{l}\text { Contrast } \\
\text { Echo }\end{array}$ & p- value \\
\hline Number of patients & 1 & 3 & $\begin{array}{l}<0.05 \\
\text { (Significant) }\end{array}$ \\
\hline $\begin{array}{l}\text { Percentage of } \\
\text { patients }\end{array}$ & 4 & 12 & \\
\hline
\end{tabular}

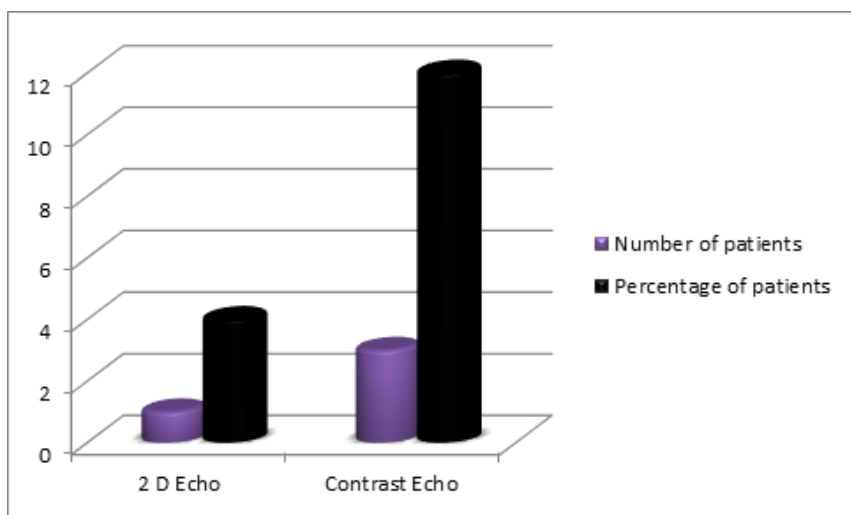

Figure 1: Prevalence of LV thrombus by 2D Echo and contrast Echo

\section{Discussion}

The present study was conducted with the aim of comparing the efficacy of $2 \mathrm{D}$ echo and contrast echo in detection of thrombus. A total of 25 patients were analyzed. Mean age of the patients of the present study was 52.5 years. Among these 25 patients, 15 were males while the remaining 10 were females. Larsson MK et al determined its ultrasonic diagnostic features, we evaluated the endocardial border delineation as visualized in a porcine model and the concomitant effect on physiological variables. Three doses of the novel polymer-shelled CA $(1.5 \mathrm{ml}, 3 \mathrm{ml}$, and $5 \mathrm{ml}$ $[5 \times 108$ microbubbles $(\mathrm{MBs}) / \mathrm{ml}])$ and the commercially available CA SonoVue $(1.5 \mathrm{ml}[2-5 \times 108 \mathrm{MBs} / \mathrm{ml}])$ were used. Visual evaluations of ultrasound images of the left ventricle were independently performed by three observers who graded each segment in a 6-segment model as either $0=$ not visible, $1=$ weakly visible, or $2=$ visible. When comparing the endocardial border delineation capacity for different regions SonoVue showed significantly higher segment scores for base and mid, except for the mid region when injecting $1.5 \mathrm{ml}$ of the polymer-shelled CA. Neither high nor low doses of the polymer-shelled CA significantly affected the investigated physiological variables. This study demonstrated that the novel polymer-shelled CA can be used in contrast-enhanced diagnostic imaging without influence on major physiological variables. ${ }^{[7]}$

In the present study, mean BMI of the patients of the present study was $27.6 \mathrm{Kg} / \mathrm{m} 2$. $2 \mathrm{D}$ echo detected thrombus in 3 percent of the cases while the contrast echo detected thrombus in 12 percent of the cases. Significant results were obtained while comparing the prevalence of thrombus as detected by $2 \mathrm{D}$ echo and contrast echo. de Haan $\mathrm{S}$ et al compared LVEF assessment by CMR and echocardiography in a heart failure population and evaluated effects on eligibility for device therapy. 152 patients (106 male, mean age 65.5 \pm 9.9 years) referred for device therapy were included. During evaluation of eligibility they underwent both CMR and echocardiographic LVEF assessment. CMR volumes were computed from a stack of short-axis images. Echocardiographic volumes were computed using Simpson's biplane method. The study population demonstrated an underestimation of enddiastolic volume (EDV) and end-systolic volume (ESV) by echocardiography of $71 \pm 53 \mathrm{ml}($ mean \pm SD) and $70 \pm 49$ $\mathrm{ml}$, respectively. This resulted in an overestimation of LVEF of $6.6 \pm 8.3 \%$ by echocardiography compared with CMR (echocardiographic LVEF $31.5 \pm 8.7 \%$ and CMR LVEF $24.9 \pm 9.6 \%$ ). $28 \%$ of patients had opposing outcomes of eligibility for cardiac device therapy depending on the imaging modality used. They found EDV and ESV to be underestimated by echocardiography, and LVEF assessed by CMR to be significantly smaller than by echocardiography. ${ }^{[8]}$ Pellikka PA et al in 2018 determined the intermodality variability of LVEF measured by echocardiography, gated single-photon emission computed tomography (SPECT), and cardiovascular magnetic resonance (CMR) in patients with left ventricular dysfunction. International multicenter diagnostic study with LVEF imaging performed at 127 clinical sites in 26 countries from July 24, 2002, to May 5, 2007, and measured by core laboratories. Secondary study of clinical diagnostic measurements of LVEF in the Surgical Treatment for Ischemic Heart Failure (STICH), a randomized trial to identify the optimal treatment strategy for patients with LVEF of $35 \%$ or less and coronary artery disease. Left ventricular ejection fraction was measured by a core laboratory for each modality independent of the results of other modalities, and measurements were compared among imaging methods using correlation, Bland-Altman plots, and coverage probability methods. Association of LVEF by each method and death was assessed. RESULTS A total of 2032 patients (mean [SD] age, 60.9 [9.6] years; 1759 [86.6\%] male) with baseline LVEF data were included. Correlation of LVEF between modalities was $r=0.601$ (for biplane echocardiography and SPECT $[\mathrm{n}=385]), \mathrm{r}=0.493$ (for biplane echocardiography and CMR $[\mathrm{n}=204]$ ), and $\mathrm{r}=$ 0.660 (for CMR and SPECT [ $\mathrm{n}=134]$ ). Bland-Altman plots showed only moderate agreement in LVEF measurements from all 3 core laboratories with no substantial overestimation or underestimation of LVEF by any modality. The percentage of observations that fell within a range of $5 \%$ ranged from $43 \%$ to $54 \%$ between different 
imaging modalities. From the results, they concluded that there was substantial variation between modalities in LVEF determination by core laboratories. ${ }^{[9]}$

\section{Conclusion}

Under the light of above mentioned data, the authors conclude that efficacy of contrast echo s significantly higher than that of 2D echo in detecting LV thrombus. However; further studies are recommended.

\section{References}

1. Devereux RB, Roman MJ, Palmieri V, et al. Prognostic implications of ejection fraction from linear echocardiographic dimensions: the Strong Heart Study. Am Heart J 2003;146:527-34.

2. Delewi R, Nijveldt R, Hirsch A, et al. Left ventricular thrombus formation after acute myocardial infarction as assessed by cardiovascular magnetic resonance imaging. Eur J Radiol 2012;81: 3900-4.

3. Weinsaft JW, Kim HW, Crowley AL, et al. LV thrombus detection by routine echocardiography: insights into performance characteristics using delayed enhancement CMR. J Am Coll Cardiol Img 2011;4:70212 .

4. Lang RM, Badano LP, Mor-Avi V, et al. Recommendations for cardiac chamber quantification by echocardiography in adults: an update from the American Society of Echocardiography and the European Association of Cardiovascular Imaging. J Am Soc Echocardiogr 2015;28:1-39.e14.

5. Asinger RW, Mikell FL, Elsperger J, Hodges M. Incidence of leftventricular thrombosis after acute transmural myocardial infarction. Serial evaluation by two-dimensional echocardiography. N Engl J Med 1981;305:297-302.

6. Kupper AJ, Verheugt FW, Peels CH, Galema TW, Roos JP. Left ventricular thrombus incidence and behavior studied by serial twodimensional echocardiography in acute anterior myocardial infarction: left ventricular wall motion, systemic embolism and oral anticoagulation. J Am Coll Cardiol 1989;13:1514-20.

7. Larsson MK, Larsson M, Nowak G, et al. Endocardial border delineation capability of a novel multimodal polymer-shelled contrast agent. Cardiovasc Ultrasound. 2014;12:24. Published 2014 Jul 3. doi:10.1186/1476-7120-12-24

8. de Haan S1, de Boer K, Commandeur J, Beek AM, van Rossum AC, Allaart CP. Assessment of left ventricular ejection fraction in patients eligible for ICD therapy: Discrepancy between cardiac magnetic resonance imaging and 2D echocardiography. Neth Heart J. 2014 Oct;22(10):449-55. doi: 10.1007/s12471-014-0594-0.

9. Pellikka PA, She L, Holly TA, Lin G, Varadarajan P, Pai RG et al. Variability in Ejection Fraction Measured By Echocardiography, Gated Single-Photon Emission Computed Tomography, and Cardiac Magnetic Resonance in Patients With Coronary Artery Disease and Left Ventricular Dysfunction. JAMA Network Open. 2018;1(4):e181456.

Copyright: (C) the author(s), 2019. It is an open-access article distributed under the terms of the Creative Commons Attribution License (CC BY 4.0), which permits authors to retain ownership of the copyright for their content, and allow anyone to download, reuse, reprint, modify, distribute and/or copy the content as long as the original authors and source are cited.

How to cite this article: Razdan M, Chouhan B. Assessment of Efficacy of 2D Echo and Contrast Echo in Detection of Thrombus. Asian J. Med. Res. 2019;8(1):ME03-ME05.

DOI: dx.doi.org/10.21276/ajmr.2019.8.1.ME2

Source of Support: Nil, Conflict of Interest: None declared. 